\title{
Quantitative Lineage Analysis of the Origin of Frog Primary Motor and Sensory Neurons from Cleavage Stage Blastomeres
}

\author{
Sally A. Moody \\ Departments of Anatomy and Cell Biology and of Neuroscience, University of Virginia School of Medicine, Charlottesville, \\ Virginia 22908
}

\begin{abstract}
The average number of primary motoneurons and RohonBeard neurons that descend from each "identified" blastomere of the 16- and 32-cell stages of the frog Xenopus laevis was determined. The dorsal, animal blastomeres are the major motoneuron progenitors, and the ventral, animal blastomeres are the major Rohon-Beard progenitors. Cells along the midline primarily give rise to only one of these phenotypes, whereas cells along the frontal plane, which separates dorsal from ventral, give rise to both phenotypes. Each blastomere produces a characteristic number of each type of neuron, with only small variations between embryos. The mean values were used to construct quantitative retrospective lineage diagrams for the first 5 cell cycles after fertilization. These diagrams illustrate that the fate to become a major neuronal progenitor is segregated as early as the 4-cell stage. The lineage patterns of which sister cell makes the majority of primary neurons at each cleavage after the 4-cell stage are quite similar for both neurons in the D lineage but only moderately similar for both neurons in the $V$ lineage. The pattern of predominant Rohon-Beard neuron fate is very similar in the $D$ and $V$ lineages. Analysis of the axial distribution of the primary motoneurons and RohonBeard neurons that descend from each blastomere indicates that the major progenitors contribute neuronal descendants periodically, to nearly every segmental bin, but the minor progenitors distribute neuronal descendants randomly along the axis. These data demonstrate that primary neuronal phenotype, cell number, predominant lineal pattern, and in some cases segmental distributlon are highly regular across a large population of embryos. This population consistency suggests that several features of neuronal fate may be influenced either by cell position or lineage.
\end{abstract}

The developmental potential of each blastomere to produce specific phenotypes is difficult to determine in vertebrate embryos. Fate maps originally relied upon vital dye staining that was not confined to a single cell and did not label the entire clone (e.g., Vogt, 1929; Keller, 1975; Nakamura et al., 1978).

\footnotetext{
Received Oct. 31, 1988; revised Feb. 3, 1989; accepted Feb. 9, 1989.

This work was supported by NIH grants NS20604 and NS23158 and an Alfred P. Sloan Research Fellowship. I would like to thank Angelika Buchheim, Daniel Best, and David Stein for their technical assistance, Kathryn Kersey for excellent graphics and photography, Mary Staton and Lydia Briscoe for typing the text, and Dr. Steven Klein for critical comments on the manuscript.

Correspondence should be addressed to Dr. Sally A. Moody, Department of Anatomy and Cell Biology, Box 439, Health Sciences Center, University of Virginia, Charlottesville, V $\Lambda 22908$.

Copyright $\circledast 1989$ Society for Neuroscience $0270-6474 / 89 / 082919-12 \$ 02.00 / 0$
}

The visualization of the embryonic ancestry of specific phenotypes from single blastomeres in yolk-laden, opaque embryos was accomplished by the use of intracellular tracer molecules (Jacobson and Hirose, 1978; Weisblat et al., 1978, 1980b). This technique has been used in frog embryos (Xenopus laevis) to map the fates of each cleavage stage blastomere (Masho and Kubota, 1986; Dale and Slack, 1987; Klein, 1987; Kline and Moody, 1987; Moody, 1987a, b; Takasaki, 1987), to determine which blastomeres produce the CNS (Jacobson and Hirose, 1978, 1981; Hirose and Jacobson, 1979; Jacobson, 1983), and to determine which blastomeres produce specific neurons (Jacobson, 1981a; Jacobson and Moody, 1984).

The present report extends those studies with a quantitative analysis of the number, predominant lineal pattern, and spatial distribution of 2 so-called primary neurons from individual, identified, early cleavage stage blastomeres. Primary neurons are the earliest neurons to differentiate (Lamborghini, 1980; Roberts and Clarke, 1982) and are involved in the early reflex responses of the tadpole (Coghill, 1913; Stehouwer and Farel, 1980; Roberts et al., 1981; Clarke et al., 1984). Two primary neurons of the spinal cord, the primary motoneuron (PMN) and the primary sensory neuron, the Rohon-Beard neuron (RB), are ideal subjects for a quantitative lineage analysis. Each population is small (Lamborghini, 1980; Jacobson, 1981a; Jacobson and Moody, 1984), and each cell has a characteristic morphology (Coghill, 1913; Hughes, 1957, 1959; Blight, 1978; Lamborghini, 1980; Nordlander, 1984), making them suitable for cell-counting procedures. Furthermore, they are among the earliest neurons to complete their final mitosis (Lamborghini, 1980), and they become terminal cells in their lineage early in development (at about the 14th generation for RB and the 16th-18th generation for PMN; Jacobson and Moody, 1984).

In order to make useful predictions concerning the commitment to and regulation of vertebrate neuronal progenitors, one needs to know the developmental mechanisms by which cell numbers are controlled. For example, it has been suggested that lineage may define the number of particular neurons that descend from cach progenitor (Hcrrup, 1987). Thercforc, I studied the number of PMN and RB that descend from each blastomere that results from stereotypic cleavage patterns (i.e., ones in which each blastomere could be considered an "identified cell"; Goodman, 1976) at the 16- and 32-cell stages. Previous study of these blastomeres revealed a high degree of regularity of cell fate; each blastomere consistently populated a particular amount of a specific region in each organ system. However, due to limitations in 3-dimensional mapping, the amount of contribution and the variability between embryos has only been estimated (Dale and Slack, 1987; Moody, 1987a, b). The cell counts reported here 
Figure 1. Right side of a $16 \mathrm{CS}$ (left) and $32 \mathrm{CS}$ (right) embryo illustrating the blastomere nomenclature (from Hirose and Iacobson, 1979; Jacobson and Hirose, 1981) used in this study. The animal pole refers to the presumptive head region, and the vegetal pole refers to the presumptive tail region.
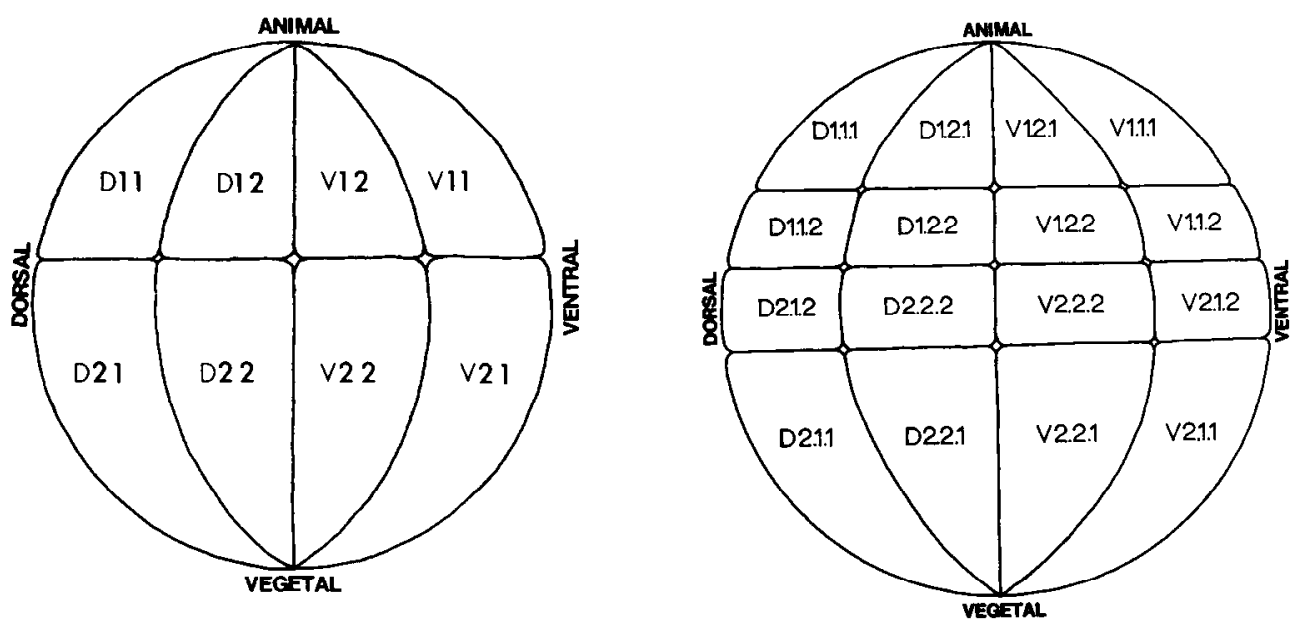

demonstrate that each blastomere is characterized by the number of PMN and RB that it will produce, with only small variations among embryos. The cell counts also were used to construct retrospective lineage diagrams for the first 5 cell cycles (2- to 32-cell stage). These diagrams allow examination of earlier stages, during which cell fate decisions may be made, which cannot be studied directly due to the physical overlap of the labeled progeny. They demonstrate the major lineal pattern of division of primary neuronal fate. Additionally, the location of PMN and RB descendants of each blastomere was mapped to determine if the clones are dispersed in a segmental nature, as in the leech (Zackson, 1982) and fish (Kimmel and Warga, 1986). These data will allow us to monitor specific fate changes in manipulated embryos to test whether the blastomere position, their lineage, or other cellular interactions are ultimately responsible for the early control of amphibian neuronal fate.

\section{Materials and Methods}

Embryo selection. Fertilized Xenopus laevis eggs were obtained by gonadotropin-induced matings of adult frogs. Jelly coats were removed from fertilized eggs by incubating them in $5 \mathrm{~mm}$ dithiothreitol buffered with 0.05 M HEPES, pH 8.9 , and washing them in $100 \%$ Steinberg's solution. The embryos were selected at the early 2-cell stage if the first cleavage furrow bisected a palely pigmented region of the animal hemisphere; this selection procedure allows one to accurately identify the dorsal hemisphere at later stages (Klein, 1987). Subsequent cleavages were monitored, and only embryos with stereotypic radial cleavage patterns were injected at the 16- and 32-cell stages (Fig. 1; the nomenclature used for each blastomere is that assigned by Hirose and Jacobson, 1979; Jacobson and Hirose, 1981). Complete descriptions of the selection of these stereotyped patterns are given in previous reports (Moody, $1987 \mathrm{a}, \mathrm{b}$ ). Only embryos, with the same cleavage patterns were used in order to ensure that consistent patterns of cytoplasmic parceling during cleavages were studied.

Blastomere injection and embryo culture. One nanoliter of a $5-10 \%$ aqueous solution of HRP (Boehringer-Mannheim) was pressure injected into one identified blastomere per embryo. Embryos were discarded if the injected blastomere extruded cytoplasm, or if it did not divide in synchrony with the uninjected blastomeres. We observed significantly fewer damaged embryos and more intense intracellular labeling with the Boehringer-Mannheim HRP compared to HRP from other sources.

Embryos were raised in a $20^{\circ} \mathrm{C}$ incubator. They were fixed by immersion in $2.5 \%$ glutaraldehyde, $1 \%$ paraformaldehyde, $0.5 \%$ dimethyl sulfoxide in $0.1 \mathrm{M}$ phosphate buffer, $\mathrm{pH} 7.4$, at stages 32-34 (Nieuwkoop and Faber, 1964). At these stages, fully differentiated PMN (Hughes, 1959; Muntz, 1964) and RB (Lamborghini, 1980; Jacobson, 198 la) can be identified (Fig. 2). Embryos were serially sectioned in the transverse plane with a cryostat and histochemically processed for the HRP reaction as described previously (Moody, 1987a).

Tissue analysis. All tissue sections between the caudal edge of the otocyst and the last segmented somite at the level of the proctodeum were scanned for HRP-filled cells. The otocyst can be used as a consistent demarcation between spinal and cranial motoneurons at these early stages because postotic cranial nuclei (IX, $X$, and XI) are not yet differentiated. The proctodeum was used as the caudal border because the curvature of the postproctodeal spinal cord makes it difficult to identify primary neurons. In addition, restriction of cell counts to within these borders kept analyses between embryos, which were fixed at different stages of axial maturation, as consistent as possible.

Cell counting procedures. HRP-labeled PMN and RB (Fig. 2) were counted in every tissue section between the rostral and caudal boundaries described above, using criteria previously described (Jacobson and Moody, 1984). All cell counts were made at $\times 600$ and were corrected for split cell errors according to the methods of Konigsmark (1970). One hundred and four embryos that were injected at the 16-cell stage (16CS) and 210 embryos that were injected at the 32-cell stage (32CS) were subjects for cell-counting procedures. The cell counts include at least 12 embryos in which the same "identified" blastomere was injected. Cell counts of clones initiated at later stages (128-512CS) were reported previously (Jacobson and Moody, 1984), but because of internal cleavages, account only for the surface members of the clones. Cell counts of clones initiated at earlier stages (2-8CS) cannot be done accurately because the spinal cord is filled with labeled cells that obscure individual neuronal morphology, especially of the PMN. Therefore, the cell counts obtained at the $16 \mathrm{CS}$ and $32 \mathrm{CS}$ were used to estimate, retrospectively, the numbers that descend from earlier stages.

Retrospective lineage diagrams. Retrospective lineage diagrams showing the percentage of a mother cell's PMN and RB progeny that each daughter cell produces were constructed by adding the means of 2 sister cells, starting at the $32 \mathrm{CS}$, to give an estimated mean for the mother cell. This procedure seems reasonable because the mean values of the $16 \mathrm{CS}$ mother cells were not statistically different from the sum of the means of their 32CS daughter cells (Table 1). The percentage of the mother cell's primary neuron progeny that each $32 \mathrm{CS}$ daughter cell produced was derived using the estimated mother cell mean (EMCM) as the denominator and the daughter cell mean from Table 1 as the numerator. The EMCM for the $16 \mathrm{CS}$ was used rather than the raw data in order to be consistent with the remaining analyses in which only the EMCMs were available. The 16CS EMCMs of 2 sisters were summed to produce the $8 \mathrm{CS}$ EMCMs. Then, the 16CS EMCM was used as the numerator and the $8 \mathrm{CS}$ EMCM was used as the denominator to derive the percentages for each $16 \mathrm{CS}$ blastomere. This process was repeated retrospectively to the $2 \mathrm{CS}$, at which time the 2 blastomeres are bilaterally symmetrical pairs (Klein, 1987), and thus are indistinguishable in fate.

Analysis of axial distribution. In order to estimate the axial distribution of each primary neuron in a clone, the embryos were divided into 9 bins between the otocyst and the proctodeum. Each segmental bin consisted of a row of tissue sections that constituted 200-300 $\mu \mathrm{m}$ of axial length, approximating the length of 2 somitic segments. The variation in length was necessary because (1) the exact segmental bound- 


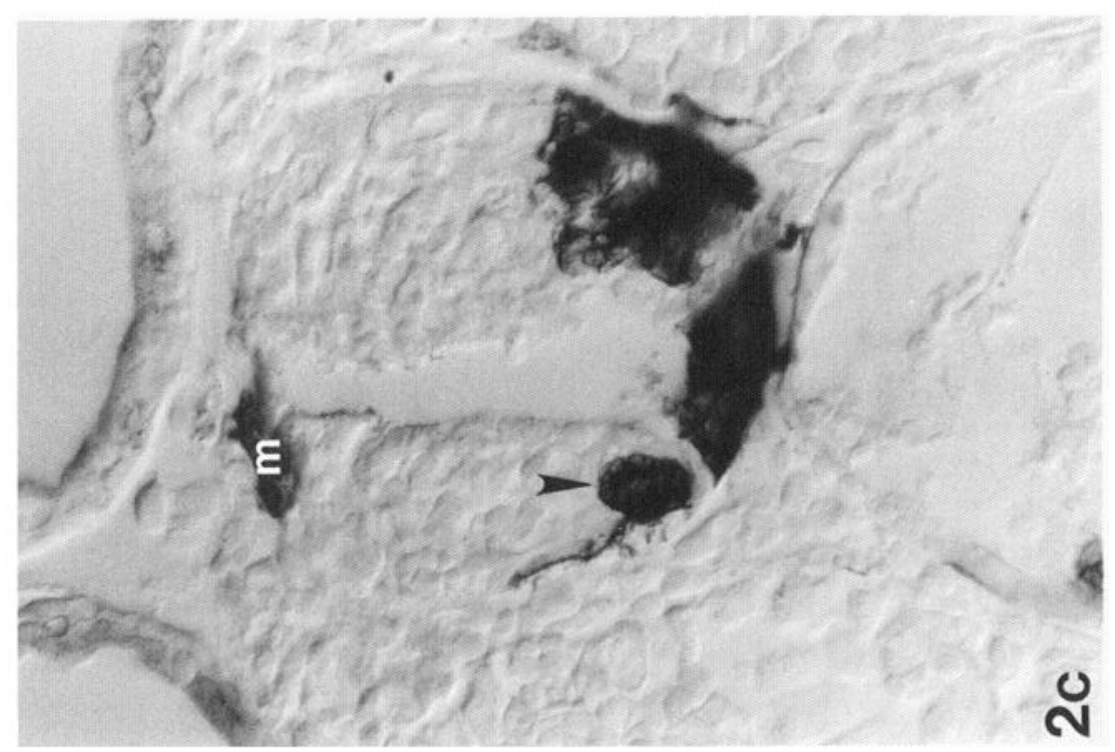

ชุ่

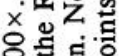

年

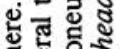

है.

영 라

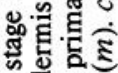

\%

制。

记

0 .

要

है

을

晋行

i

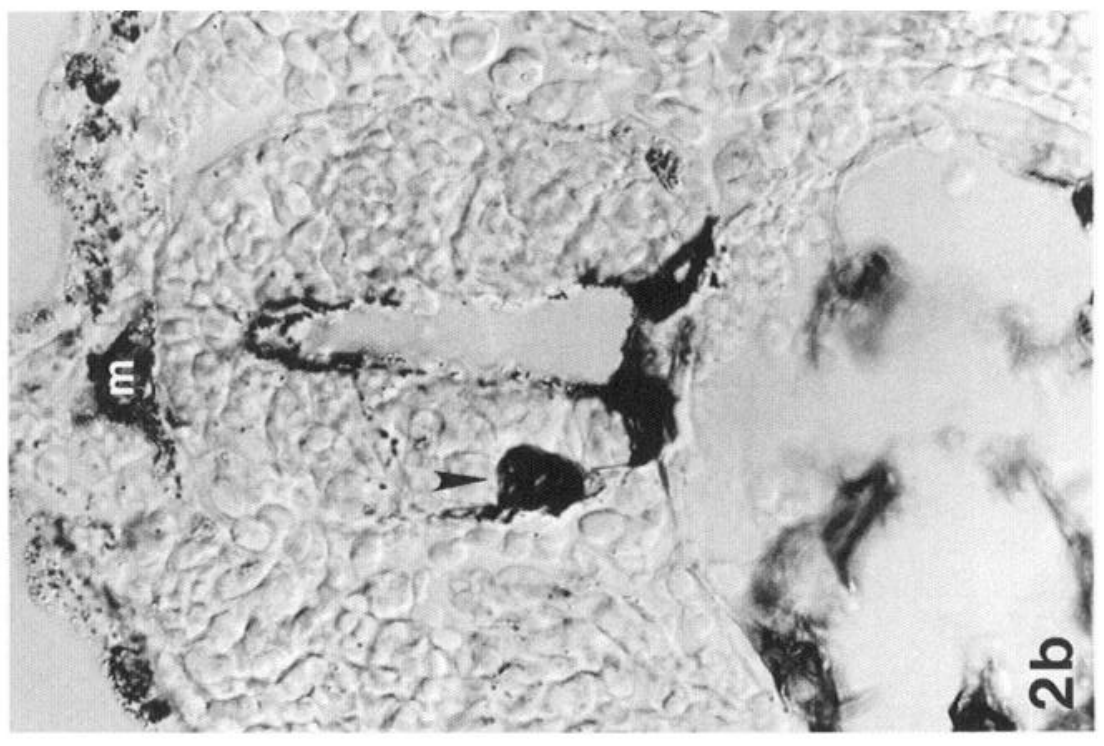

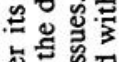

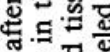

늘 过

工乎

둥료

政

诃

可空

눙웅

证

긍

등 댔

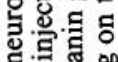

돌

क

덩

웅ㅎㅁ담

돈 능

해웡

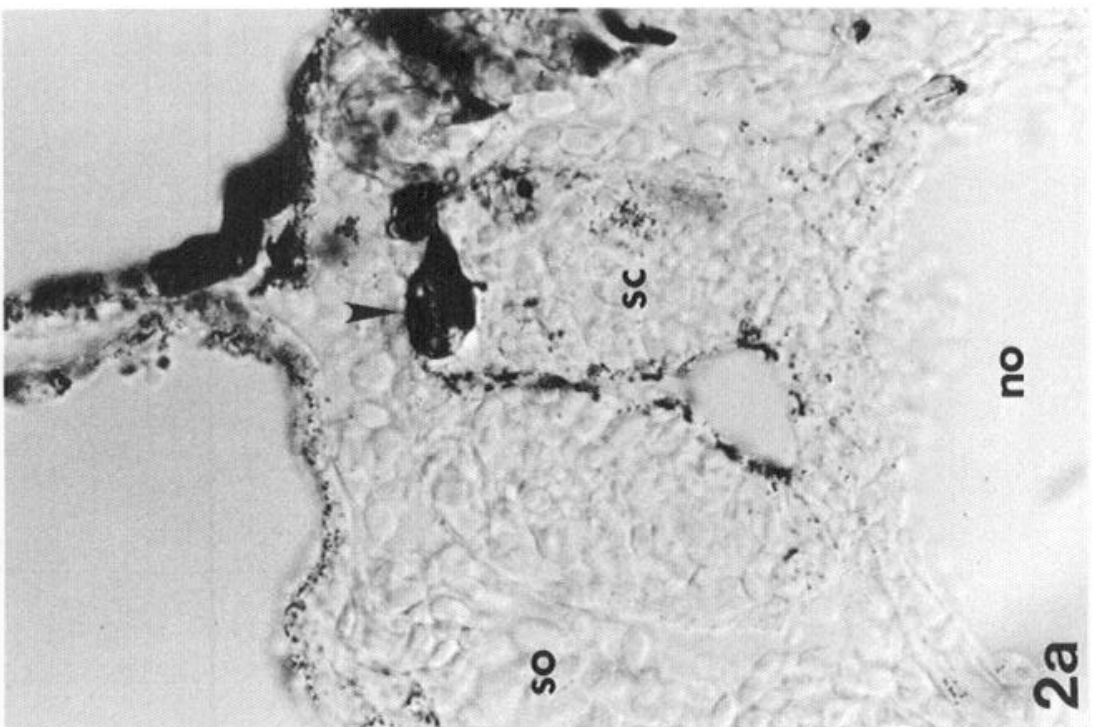

준

응

응 踏

능대대 둥

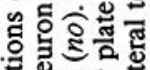

氙항형

ఊึ

응 형은

空要

\%

政

돈 $气$ 응

2.

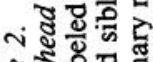

웡

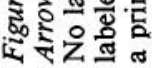




\begin{tabular}{|c|c|c|c|}
\hline Blastomere & $n$ & PMN ( \pm SEM) & $\mathrm{RB}( \pm \mathrm{SEM})$ \\
\hline D1.1 & 15 & $42.53(2.64)$ & $1.47(0.41)$ \\
\hline D1.1.1 & 14 & $18.79(2.19)$ & $0.79(0.12)$ \\
\hline D1.1.2 & 13 & $24.94(2.72)$ & $0.67(0.14)$ \\
\hline Sum of $32 \mathrm{CS}$ & & 43.73 & 1.46 \\
\hline $\mathrm{D} 1.2$ & 12 & $36.50(4.61)$ & $4.92(1.06)$ \\
\hline D1.2.1 & 13 & $20.72(3.11)$ & $1.85(0.41)$ \\
\hline $\mathrm{D} 1.2 .2$ & 14 & $13.54(1.45)$ & $2.86(0.54)$ \\
\hline Sum of $32 \mathrm{CS}$ & & 34.26 & 4.71 \\
\hline D2.1 & 12 & $5.00(1.88)$ & $0.42(0.33)$ \\
\hline $\mathrm{D} 2.1 .2$ & 13 & $1.92(0.71)$ & $0.15(0.15)$ \\
\hline $\mathrm{D} 2.1 .1$ & 12 & $0.67(0.58)$ & 0 \\
\hline Sum of $32 \mathrm{CS}$ & & 2.59 & 0.15 \\
\hline $\mathrm{D} 2.2$ & 12 & $8.59(2.66)$ & $3.42(0.82)$ \\
\hline $\mathrm{D} 2.2 .2$ & 15 & $10.05(1.75)$ & $4.20(1.46)$ \\
\hline $\mathrm{D} 2.2 .1$ & 13 & $0.54(0.33)$ & $0.08(0.08)$ \\
\hline Sum of $32 \mathrm{CS}$ & & 10.59 & 4.28 \\
\hline V1.1 & 13 & $0.31(0.23)$ & $10.40(2.13)$ \\
\hline V1.1.1 & 13 & 0 & $2.42(0.72)$ \\
\hline $\mathrm{V} 1.1 .2$ & 13 & 0 & $4.65(1.54)$ \\
\hline Sum of $32 \mathrm{CS}$ & & $0^{a}$ & 7.07 \\
\hline $\mathrm{V} 1.2$ & 14 & $3.86(2.36)$ & $24.40(2.91)$ \\
\hline V1.2.1 & 12 & $2.17(1.09)$ & $8.92(1.85)$ \\
\hline $\mathrm{V} 1.2 .2$ & 13 & $1.31(0.98)$ & $9.38(0.70)$ \\
\hline Sum of $32 \mathrm{CS}$ & & 3.48 & $18.3^{a}$ \\
\hline $\mathrm{V} 2.1$ & 13 & 0 & $0.54(0.24)$ \\
\hline $\mathrm{V} 2.1 .2$ & 12 & 0 & $3.42(0.79)$ \\
\hline V2.1.1 & 15 & 0 & $0.60(0.34)$ \\
\hline Sum of $32 \mathrm{CS}$ & & 0 & $4.02^{a}$ \\
\hline V2.2 & 13 & $0.54(0.40)$ & $13.2(2.90)$ \\
\hline $\mathrm{V} 2.2 .2$ & 13 & $0.77(0.25)$ & $14.8(1.76)$ \\
\hline $\mathrm{V} 2.2 .1$ & 12 & $0.33(0.18)$ & $2.4(1.10)$ \\
\hline Sum of $32 \mathrm{CS}$ & & 1.10 & 17.2 \\
\hline
\end{tabular}

a Denotes that the sum of $32 \mathrm{CS}$ daughters does not fall within the mean \pm SEM of the $16 \mathrm{CS}$ mother cell. aries in the spinal cord could not be reconstructed from transverse tissue sections, due to the chevron shape of the somite; and (2) the length of the somite varies from $150 \mu \mathrm{m}$ rostrally to about $100 \mu \mathrm{m}$ caudally (Hamilton, 1969). The number of labeled PMN and RB in each segmental bin was tabulated for each embryo, and the average contribution of each blastomere to each segmental bin was determined.

\section{Results}

\section{Quantitative fate maps}

The average numbers of PMN and RB produced by each blastomere are reported in Table 1 . A mean value of less than 1 for a blastomere indicates that only a few embryos in the group had 1 or a few labeled primary neurons. The SEMs for each blastomere are fairly small for cases in which more than 1 cell was counted, demonstrating that these mean values do not vary significantly within the population. The sum of the mean number of PMN from all blastomeres is 100 for the 16CS data, and 98 for the $32 \mathrm{CS}$ data. The sum of the mean number of RB from all blastomeres is 58 for the $16 \mathrm{CS}$ data, and 59 for the $32 \mathrm{CS}$ data. Thus, the data from a large number of embryos are consistent and closely match the known numbers of these cells on each side of the spinal cord (adjusted for developmental stage; Lamborghini, 1980; Jacobson and Moody, 1984).

The majority ( $81 \%$ ) of PMN descend from the dorsal, animal blastomeres (D1.1, D1.2 and their daughters; Fig. 3). In the dorsal, vegetal quadrant, the blastomeres on the frontal plane (D2.2 and its anterior daughter, D2.2.2) contribute a significant proportion of PMN $(\sim 10 \%)$ to the total population. The remaining dorsal blastomeres contribute very few PMN. In the ventral hemisphere, only blastomere V1.2 and its daughters are consistent progenitors of a few PMN. The other ventral blastomeres on the frontal plane (V2.2, V2.2.2, V2.2.1) occasionally give rise to a few PMN (2 embryos out of 13; 7 embryos out $13 ; 3$ embryos out of 12 , respectively). The blastomeres on the ventral midline do not contribute to the PMN population, with one exception; one embryo in which V1.1 was labeled at the $16 \mathrm{CS}$ contained $3 \mathrm{PMN}$.

The blastomeres that are ancestral to RB are arranged in nearly a mirror image to those that are ancestral to PMN (Fig. 3). The ventral, animal blastomeres (V1.1, V1.2, and their daughters) give rise to the majority (58 and $43 \%$, respectively) of $\mathrm{RB}$. The ventral, vegetal blastomeres on the frontal plane (V2.2 and its daughters) also give rise to significant numbers
Figure 3. Mean number of primary motoneurons (closed, black numbers) and Rohon-Beard neurons (open numbers) derived from each 16CS (left) and $32 \mathrm{CS}$ (right) blastomere. Orientation is the same as in Figure 1.
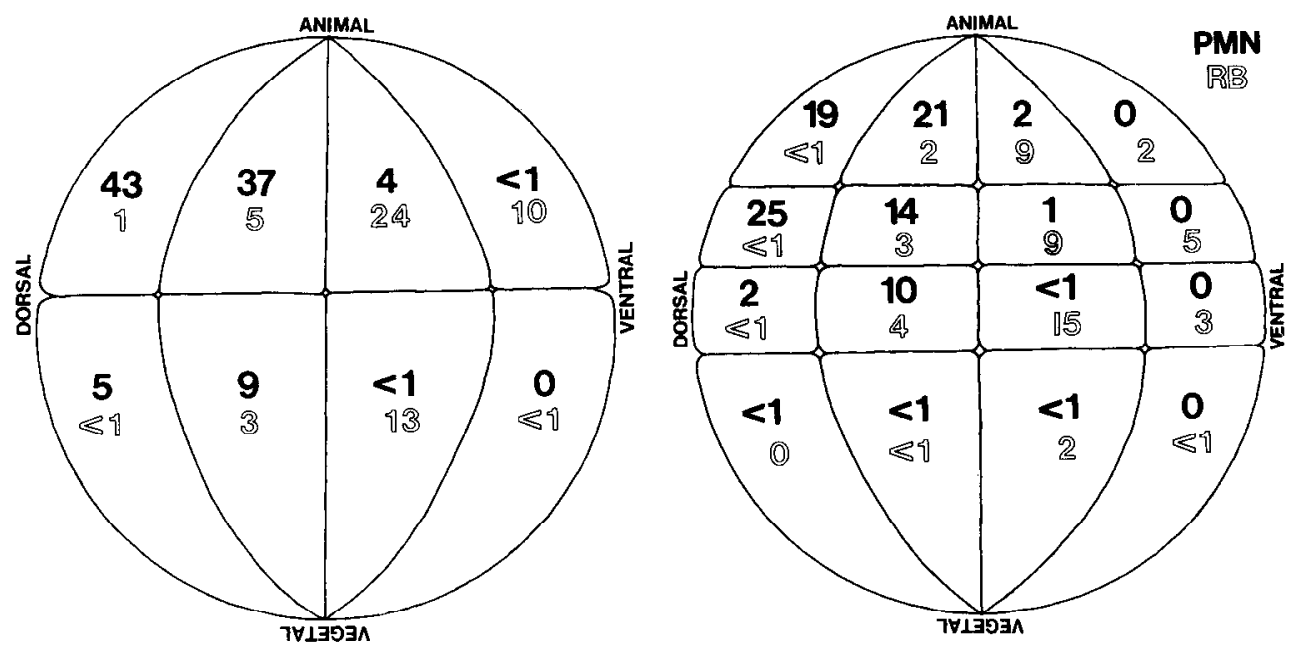
PRIMARY MOTONEURON LINEAGE

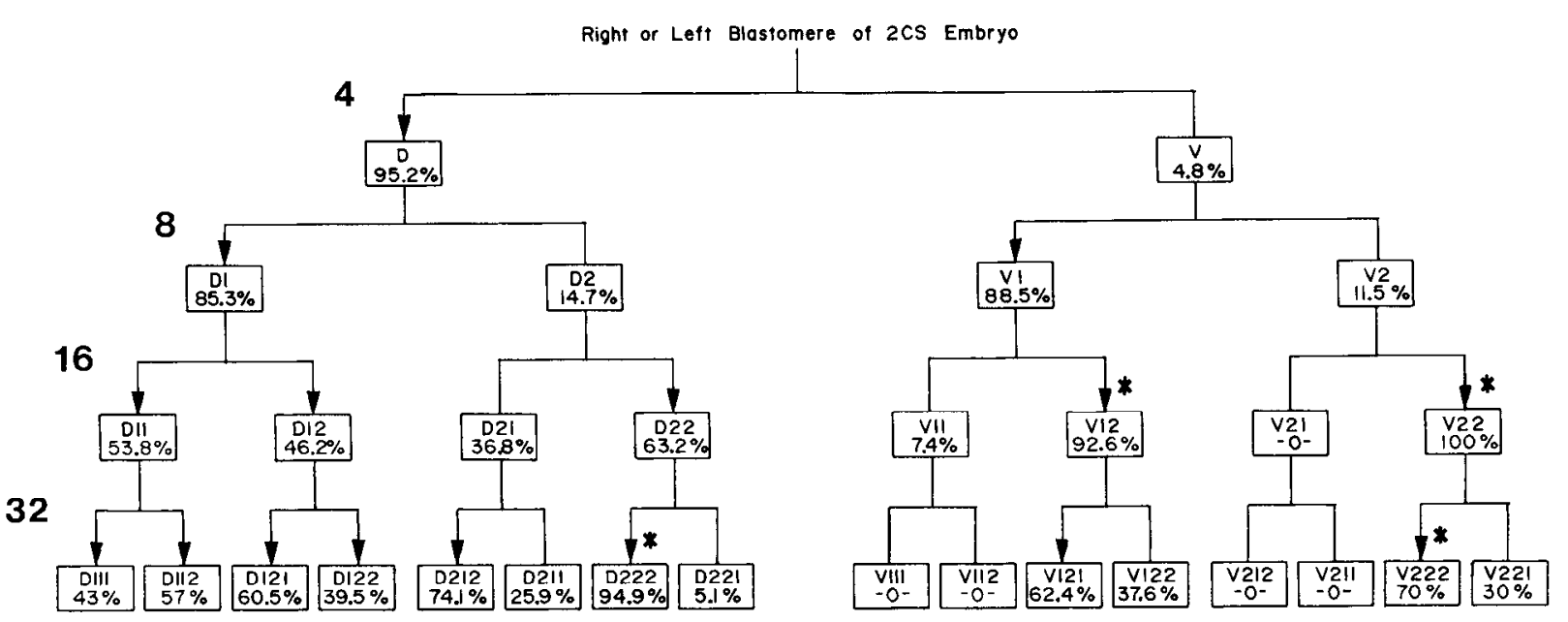

ROHON-BEARD NEURON LINEAGE

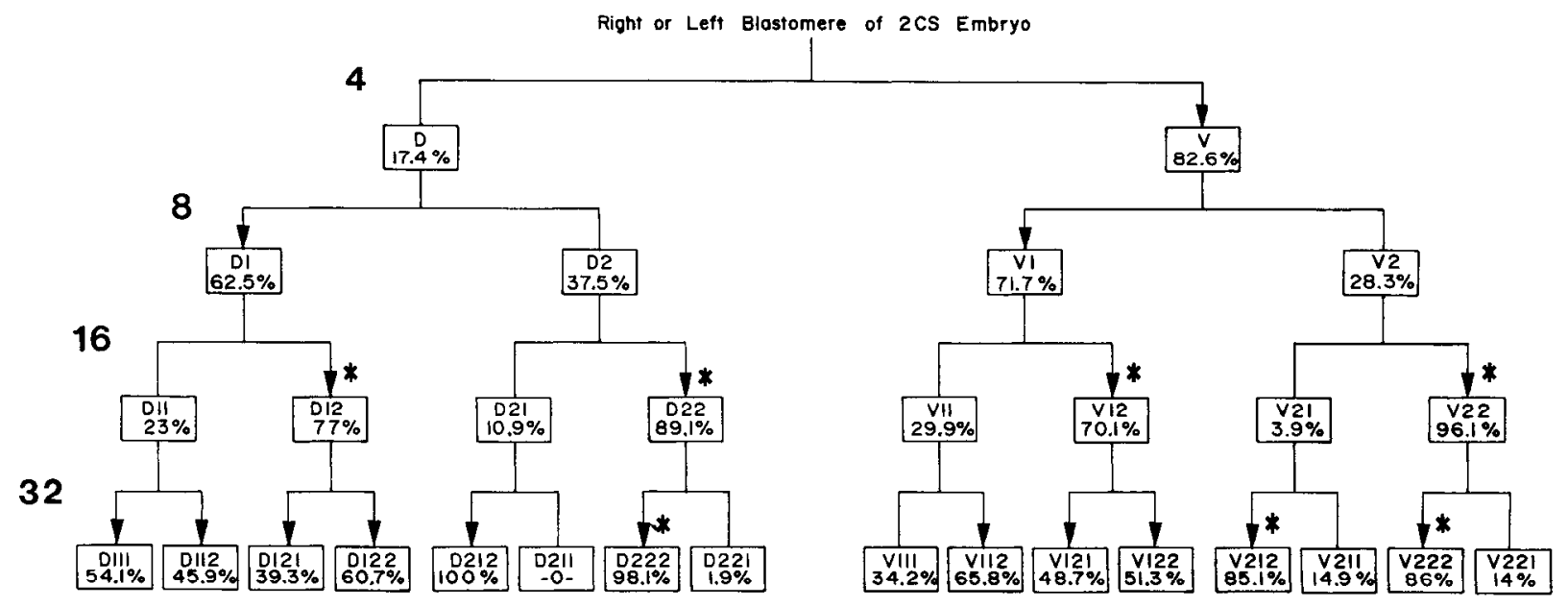

Figure 4. Retrospective lineage diagrams of PMN and RB for the first 5 cell cycles after fertilization. Numbers in the left margin indicate the cell stage of each branch of the family tree. The values in each box indicate the percentage of neurons that each blastomere contributes to its mother cell's value. Arrowheads denote the major pattern of division of primary neuron fate. If sisters contribute approximately equally ( $<61 \%$ each), they both are marked with arrowheads. If sisters contribute unequally (i.e., one is $>61 \%$ ), only the major progenitor is marked with an arrowhead. In the latter group, the numerical values of the sister contributions (mean \pm SEM) were compared among $16 \mathrm{CS}$ and $32 \mathrm{CS}$ blastomeres, using the values in Table 1. Asterisks indicate those blastomeres whose actual cell counts do not overlap with those of their sisters, and thus are significantly different.

( $\sim 25 \%)$ of $\mathrm{RB}$, but the remaining ventral blastomeres (V2.1 and its daughters) hardly contribute RB. The dorsal blastomeres on the frontal plane (D1.2, D2.2, and their daughters) each give rise to a few RB, and the dorsal, midline blastomeres (D1.1, $\mathrm{D} 2.1$, and their daughters) give rise to only an occasional RB.

Table 1 compares the average number of $\mathrm{PMN}$ and $\mathrm{RB}$ that descend from each 16CS blastomere to the sum of the mean number of PMN and RB that descend from that blastomere's $32 \mathrm{CS}$ daughters. In nearly every case the sum of the daughters $( \pm$ the largest SEM) is not significantly different from the mean number $( \pm$ SEM) of the mother cell. Thus, within a large population of cmbryos ( $n>30$ per blastomerc), the numerical data are not random, but are very consistent. These comparisons also illustrate how the numerical fates are distributed to each daughter cell at the cleavage cycle between the $16 \mathrm{CS}$ and the
$32 \mathrm{CS}$. In some cases, each daughter produced approximately half the number of primary neurons that the mother cell produced (e.g., DI.1, V1.2). In other cases the 2 daughters consistently produced very different numbers of primary neurons. For example, some daughter cells produced slightly more PMN (D1.2.1, D2.1.2, V2.2.2) or RB (D1.2.2, V1.1.2). In some cases the majority of PMN (D2.2.2) or RB (D2.1.2, D2.2.2, V2.1.2, $\mathrm{V} 2.2 .2)$ are produced by only one of the daughter cells. Thus, cell divisions at early cleavage stages divide mother cell fate quantitatively between daughter cells, either equally, unequally, or nearly exclusively.

Analysis of the distribution of cell fate to daughter cells can indicate at what developmental stages commitment to particular progeny may occur. To further explore this point, the data in Table 1 were used to construct retrospective lineage diagrams 
for the first 5 cell cycles of development (Fig. 4). These illustrations show the percentage of a mother cell's PMN and RB progeny that each daughter cell produced. (The percentages can be compared only between sisters, and not across the lineage tree, because they are directly derived from individual mother cell values.) Arrowheads in Figure 4 mark either sister cells that equally contribute PMN or RB (both $<61 \%$ ), or one sister that is the predominant PMN or RB contributor at that branch of the lineage $(>61 \%)$, and thereby indicate the major lineal pattern for these primary neurons.

There is a major division of PMN fate at the 4CS. Ninetyfive percent of all PMN descend from the dorsal (D) blastomere. At the next cleavage, $85 \%$ of D's PMN are derived from its anterior daughter (D1), and subsequently, PMN fate is nearly equally divided among the daughters, and then among the granddaughters. In the posterior branch of the D lineage (D2), most of the PMN descend from the frontal plane daughter (D2.2), specifically from the anterior granddaughter (D2.2.2). More of the PMN descendants of the dorsal midline daughter (D2.1) also descend from the anterior granddaughter (D2.1.2), although the difference from its sister is not significant. In the $\mathrm{V}$ lineage, which accounts for only $5 \%$ of the PMN, the majority $(89 \%)$ of PMN descend from the anterior daughter (V1). Of its descendants, only the frontal plane daughter (V1.2) produces significant numbers of PMN, the anterior granddaughter (V1.2.1) being the larger contributor (62\%). Only occasionally do PMN descend from the ventral, vegetal blastomere (V2). All of these rare progeny descend from its frontal plane daughter (V2.2), the majority of which (70\%) descend from the anterior granddaughter (V2.2.2). In summary, the major PMN lineal patterns are (1) the D1 descendants equally produce PMN, and (2) the D2, $\mathrm{V} 1$, and V2 clones produce PMN in nearly identical lineal patterns. However, these 3 clones account for only a minor component of the total PMN.

In the RB lineage there also is a major division of fate at the 4CS (Fig. 4). The ventral (V) blastomere is the major RB progenitor $(83 \%)$. Its anterior daughter (V1) produces the majority of these RB (72\%). At the $16 \mathrm{CS}$, the RB fate of the V granddaughters is unequally divided, with the majority of RB being produced by the blastomeres on the frontal plane (V1.2, 70\%; $\mathrm{V} 2.2,96 \%$ ). At the $32 \mathrm{CS}, \mathrm{RB}$ fate of the granddaughters of V1 is divided nearly equally. In the posterior branch (V2), the majority of RB descend from the anterior granddaughters (V2.1.2, $85 \% ; \mathrm{V} 2.2 .2,86 \%$ ). The general pattern of $\mathrm{RB}$ fate in the $\mathrm{D}$ lineage is nearly identical to that in the $\mathrm{V}$ lineage. At the $8 \mathrm{CS}$, the anterior daughter (D1) produces a slight majority of RB $(63 \%)$. At the $16 \mathrm{CS}$, the frontal plane granddaughters produce the majority of RB (D1.2, 77\%; D2.2, 89\%). At the 32CS, RB fate is divided approximately equally between sisters in the D1 lineage but is produced nearly exclusively from the anterior granddaughters of D2.

\section{Contralateral contributions}

The clones derived from Xenopus cleavage-stage blastomeres are not strictly ipsilateral to the side of injection. In many cases there were small, but consistent numbers of contralateral neuronal progeny. In fact, several organs contain a few progeny from contralateral progenitors (Jacobson and Hirose, 1978; Klein, 1987; Moody, 1987a, b). Contralateral PMN and RB were found at spinal cord levels in which there were several ipsilateral neuronal members of the clone (Fig. $2 c$ ). Contralateral PMN were observed in $60 \%$ of the D1.1 clones (mean clone size $(\bar{x}=2.9$ ) and in $14 \%(\mathrm{D} 1.1 .1, \bar{x}=4.5)$ and $38 \%(\mathrm{D} 1.1 .2, \bar{x}=5)$ of the clones of its daughters. An average of one contralateral PMN was observed in 14-17\% of clones derived from D1.2 and its equatorial daughter, and in $8 \%$ of clones derived from D2.1 and its equatorial daughter. One to 2 contralateral RB were observed in $15-27 \%$ of each $16 \mathrm{CS}$ animal hemisphere clone, in $8 \%$ of the dorsal, vegetal clones (D2.1, D2.2) and in none of the ventral, vegetal clones (V2.1, V2.2). Only four 32CS blastomeres produced $1-2$ contralateral RB (D1.1.1, 14\% of the embryos; Dl.2.2, $21 \% ; \mathrm{V} 1.2 .1,8 \% ; \mathrm{V} 1.2 .2,15 \%)$.

\section{Axial distribution of clones}

Since spatial restriction seems to occur early in Xenopus development (Jacobson, 1983; Jacobson and Klein, 1985), it is important to determine whether there is any spatial restriction with regard to the distribution of the primary neuron clones. The tissue sections containing spinal cord were divided into 9 segmental bins ranging from 200 to $300 \mu \mathrm{m}$ in length, which approximates 2 somite segments. The mean numbers of PMN in each segmental bin of embryos injected at the $16 \mathrm{CS}$ are reported in Table 2. In general, those blastomeres that make a significant contribution to the PMN population (D1.1, D1.2, D2.2) have descendants in every segmental bin. D1.1 contributes the largest percentage of PMN to rostral segmental bins, and D1.2 contributes the majority to caudal segmental bins. D2. 2 contributes a nearly constant mean number of one PMN to all segmental bins. Blastomeres D2.1 and V1.2, which make a lesser contribution to the PMN population, have, on the average, 1 or fewer PMN per segmental bin. Blastomeres V1.1 and V2.2, which hardly contribute PMN at all, have only caudally located descendants. Their near-zero average number of PMN per bin indicates that the contributions are not consistent from one embryo to the next, i.e., there is a random dispersal of the progeny along the axis of the animal.

Similar data collected for the 32CS daughters demonstrate the same general pattern (Table 3 ). The daughters of D1.1 contribute about equal numbers of PMN to every segmental bin, with a greater rostral distribution. The daughters of D1.2 contribute PMN about equally in the caudal 6 bins, but the anterior daughter (D1.2.1) contributes twice as many PMN to the rostral 3 bins. Blastomere D2.2.2 contributes about 1 PMN to each segmental bin. The rest of the blastomeres that contribute PMN to the embryo do so in a relatively random manner, as indicated by the mean values being close to zero. In order to determine whether these values significantly vary within the population, they were compared with the values derived from the $16 \mathrm{CS}$ embryos. The sums of the $32 \mathrm{CS}$ sisters were converted to percentages of the total PMN per segmental bin and compared with the same percentage derived for the mother cell. The differences nearly always ( $89 \%$ of the bins) werc smaller than $5 \%$, occasionally $(8 \%)$ were between 5 and $8 \%$, and only twice $(3 \%)$ were larger than $10 \%$ (bin 9 of D1.1 and D1.2). Thus, the distributions were consistent among all embryos.

The mean numbers of $\mathrm{RB}$ from each $16 \mathrm{CS}$ blastomere in each segmental bin are reported in Table 4. Blastomere V1.2 is the major RB progenitor, having nearly the largest contribution to all but the most rostral segmental bin. Blastomere V2.2 contributes about 1-2 RB per segmental bin, excepting the most caudal one. The other blastomeres contribute RB less regularly. D1.2 contributes about 1 or 2 cells only to rostral bins, and $\mathrm{V} 1.1$ does the same only for caudal bins. The contributions of D1.1 and D2.2 appear to be randomly distributed since their 
Table 2. Average number of PMN contributed by each 16CS blastomere to each segmental bin of spinal cord

\begin{tabular}{|c|c|c|c|c|c|c|c|c|c|}
\hline \multirow{2}{*}{$\begin{array}{l}\text { Blasto- } \\
\text { mere }\end{array}$} & \multicolumn{9}{|l|}{ Bin } \\
\hline & 1 & 2 & 3 & 4 & 5 & 6 & 7 & 8 & 9 \\
\hline D1.1 & 8.3 & 10.7 & 8.5 & 5.8 & 3.6 & 2.3 & 1.5 & 1.4 & 0.6 \\
\hline D1.2 & 6.4 & 4.9 & 5.8 & 4.5 & 4.3 & 3.2 & 2.9 & 2.9 & 2.2 \\
\hline D2.1 & 0.9 & 1.3 & 0.9 & 0.8 & 0.5 & 0.2 & 0.1 & 0 & 0.3 \\
\hline $\mathrm{D} 2.2$ & 1.0 & 0.8 & 1.0 & 1.3 & 1.3 & 0.9 & 0.9 & 1.0 & 0.8 \\
\hline V1.1 & 0 & 0 & 0 & 0 & 0 & 0 & 0 & 0.2 & 0.1 \\
\hline V1.2 & 0 & 1.1 & 0.9 & 0.3 & 0.6 & 0.4 & 0.1 & 0.4 & 0.3 \\
\hline V2.1 & 0 & 0 & 0 & 0 & 0 & 0 & 0 & 0 & 0 \\
\hline V2.2 & 0 & 0 & 0 & 0 & 0.1 & 0 & 0.1 & 0.2 & 0.1 \\
\hline Total & 16.6 & 18.8 & 17.1 & 12.7 & 10.4 & 7.0 & 5.6 & 6.1 & 4.4 \\
\hline
\end{tabular}

mean bin numbers rarely approach $1 \mathrm{RB}$. Blastomeres D2.1 and V2.1 generally do not contribute to the RB population, except for a few random cells caudally.

At the $32 \mathrm{CS}$, only V1.2.1, V1.2.2, and V2.2.2 consistently contribute 1 to $2 \mathrm{RB}$ to each segmental bin (Table 5). The blastomeres that contribute significant numbers of RB (D1.2.1, $\mathrm{D} 1.2 .2, \mathrm{D} 2.2 .2$, V1.1.1, V1.1.2, V2.1.2, V2.2.1) have values in most bins, but rarely in numbers that approach 1 , indicating random axial dispersal of the $\mathrm{RB}$ progeny. The few other blastomeres that contribute only occasional RB (D1.1.1, D1.1.2, $\mathrm{D} 2.1 .2, \mathrm{D} 2.2 .1, \mathrm{~V} 2.1 .1)$ also have randomly distributed progeny; interestingly, D1.1.1's very small contribution of RB skips every other segmental bin. Comparison of the percent contribution per bin of the sum of the $32 \mathrm{CS}$ sisters to that of the $16 \mathrm{CS}$ mother cell demonstrates that $46 \%$ of the bins varied by less than $5 \%, 25 \%$ varied by $5-10 \%$, and $29 \%$ varied by greater than $10 \%$. These variations exceeded those observed for the PMN.

\section{Discussion}

The study of embryonic cell lineage allows one to predict whether aspects of the mature body form arise via gene action (e.g., lineage), embryonic cell-cell interactions (e.g., inductions), and/ or other environmental influences (e.g., growth factors or hormones). In Xenopus alone, several laboratories have used lineage techniques in order to study the developmental fate and determination of clcavage stage blastomeres (Jacobson and Hirose, 1978, 1981; Hirose and Jacobson, 1981; Jacobson, 1981a, b, 1983, 1984; Gimlich and Gerhart, 1984; Heasman et al., 1984; Masho and Kubota, 1986; Dale and Slack, 1987; Klein, 1987; Moody, 1987a, b; Takasaki, 1987). In general, these studies all demonstrate that frog cell fate is predictably regular, albeit not invariant, in terms of the types of progeny produced and the region of the body that they populate, but they have not addressed whether "identified" blastomeres consistently produce the same number of particular progeny; these data are particularly difficult to collect because of the large number of progeny in vertebrate clones. However, we have obtained such data by studying 2 primary neurons, of which there are $<100$ on each side of the spinal cord of a tail bud embryo. These data demonstrate the degree of reproducibility in cell fate, allow us to deduce the predominant pattern of lineal descent, and estimate the periodicity of axial distribution for 2 phenotypes. This information should help us understand the roles of cell position, lineage, and environmental factors on neuronal cell fate.

Table 3. Average number of PMN contributed by each 32CS blastomere to each segmental bin of spinal cord

\begin{tabular}{|c|c|c|c|c|c|c|c|c|c|}
\hline \multirow{2}{*}{$\begin{array}{l}\text { Blasto- } \\
\text { mere }\end{array}$} & \multicolumn{9}{|l|}{ Bin } \\
\hline & 1 & 2 & 3 & 4 & 5 & 6 & 7 & 8 & 9 \\
\hline D1.1.1 & 3.0 & 5.1 & 3.7 & 2.3 & 1.4 & 1.4 & 1.2 & 1.0 & 0.5 \\
\hline D1.1.2 & 2.9 & 5.3 & 5.6 & 3.4 & 2.5 & 2.3 & 1.4 & 1.1 & 0.7 \\
\hline D1.2.1 & 2.9 & 4.7 & 3.2 & 2.2 & 2.8 & 2.2 & 2.2 & 2.2 & 0.5 \\
\hline D1.2.2 & 1.2 & 1.8 & 1.6 & 1.5 & 2.5 & 1.7 & 1.7 & 1.2 & 0.4 \\
\hline $\mathrm{D} 2.1 .2$ & 0.8 & 0 & 0.1 & 0.1 & 0.3 & 0.1 & 0.1 & 0 & 0 \\
\hline D2.1.1 & 0 & 0.2 & 0.6 & 0.3 & 0.3 & 0.2 & 0 & 0 & 0.2 \\
\hline $\mathrm{D} 2.2 .2$ & 0.5 & 0.8 & 1.1 & 1.1 & 1.3 & 1.6 & 1.7 & 1.5 & 0.4 \\
\hline $\mathrm{D} 2.2 .1$ & 0 & 0.1 & 0.1 & 0 & 0 & 0 & 0.1 & 0 & 0 \\
\hline V1.1.1 & 0 & 0 & 0 & 0 & 0 & 0 & 0 & 0 & 0 \\
\hline V1.1.2 & 0 & 0 & 0 & 0 & 0 & 0 & 0 & 0 & 0 \\
\hline V1.2.1 & 0.2 & 0.7 & 0.5 & 0.2 & 0.2 & 0.1 & 0.3 & 0.1 & 0 \\
\hline $\mathrm{V} 1.2 .2$ & 0 & 0.4 & 0.2 & 0.2 & 0.3 & 0.1 & 0.1 & 0.1 & 0 \\
\hline $\mathrm{V} 2.1 .2$ & 0 & 0 & 0 & 0 & 0 & 0 & 0 & 0 & 0 \\
\hline V2.1.1 & 0 & 0 & 0 & 0 & 0 & 0 & 0 & 0 & 0 \\
\hline $\mathrm{V} 2.2 .2$ & 0 & 0.2 & 0.1 & 0.2 & 0.2 & 0.1 & 0 & 0 & 0.1 \\
\hline $\mathrm{V} 2.2 .1$ & 0 & 0 & 0 & 0.2 & 0.1 & 0.1 & 0 & 0 & 0 \\
\hline Total & 11.5 & 19.3 & 16.8 & 11.7 & 11.9 & 9.9 & 8.8 & 7.2 & 2.8 \\
\hline
\end{tabular}


Table 4. Average number of RB contributed by each 16CS blastomere to each segmental bin of spinal cord

\begin{tabular}{|c|c|c|c|c|c|c|c|c|c|}
\hline \multirow{2}{*}{$\begin{array}{l}\text { Blasto- } \\
\text { mere }\end{array}$} & \multicolumn{9}{|l|}{ Bin } \\
\hline & 1 & 2 & 3 & 4 & 5 & 6 & 7 & 8 & 9 \\
\hline D 1.1 & 0 & 0.2 & 0.2 & 0.2 & 0.2 & 0.2 & 0.1 & 0.2 & 0 \\
\hline D1.2 & 0.8 & 1.7 & 0.7 & 0.9 & 0.1 & 0.3 & 0.2 & 0.3 & 0.2 \\
\hline D2.1 & 0 & 0 & 0 & 0 & 0 & 0 & 0.1 & 0.2 & 0.2 \\
\hline $\mathrm{D} 2.2$ & 0.6 & 0.8 & 0.3 & 0.8 & 0.6 & 0.3 & 0 & 0.1 & 0.1 \\
\hline V1.1 & 0 & 0.2 & 0.3 & 0.4 & 1.8 & 1.9 & 2.5 & 2.0 & 1.5 \\
\hline V1.2 & 0.3 & 3.2 & 3.8 & 4.5 & 3.1 & 3.4 & 2.4 & 2.3 & 1.4 \\
\hline V2.1 & 0 & 0 & 0 & 0 & 0 & 0 & 0.1 & 0.1 & 0.2 \\
\hline V2.2 & 0.9 & 2.2 & 1.8 & 1.6 & 2.1 & 1.8 & 1.2 & 1.3 & 0.3 \\
\hline Total & 2.6 & 8.3 & 7.1 & 8.4 & 7.9 & 7.9 & 6.6 & 6.5 & 3.9 \\
\hline
\end{tabular}

\section{Determinant or indeterminant lineage}

In several invertebrates, cell division patterns are determinant (e.g., Conklin, 1905; Sulston and Horvitz, 1977; Weisblat et al., 1980a; Sulston et al., 1983). That is, cell division patterns are invariant across individuals and appear to determine the fate of the progeny. In vertebrate models, this invariance has not been observed. In the zebrafish (Kimmel and Law, 1985a; Kimmel and Warga, 1987), frog (Hirose and Jacobson, 1979; Jacobson, 1981a), and mouse (Pedersen et al., 1986), the early cleavage patterns are variable. Mouse cleavage stage blastomeres are totally indistinguishable from one another, especially since the embryo has no morphological asymmetries to indicate axial polarity. In fish and frog, cleavage patterns also vary from individual to individual. However, there is a prominent stereotypic pattern for the first 5 or 6 division (Hirose and Jacobson, 1979; Kimmel and Law, 1985a; Moody, 1987a, b). Thus, although early cell division patterns are not invariant in fish or frog, there is enough regularity in some individuals to produce "identified" cells, allow clonal analyses, and determine whether stereotypic cleavages give rise to stereotypic fates.

In general, the invariant cleavage patterns of invertebrates give rise to invariant cell fates. At the other extreme, the highly variable mouse cleavage patterns coincide with highly variable cell fates, at least prior to the establishment of the inner cell mass (Ziomek et al., 1982; Pedersen et al., 1986). Similarly, cell fate in the zebrafish is indeterminant (Kimmel and Law, 1985b). After marking the same blastomere in different embryos, the clones were highly variable with regard to position and cellular phenotype (Kimmel and Warga, 1987). Although some of this inderterminancy in fate may occur because the cells cannot be identified in relation to the embryonic axes, since there are no indicators of the cardinal axes of the fish until just before gastrulation (Kimmel and Warga, 1987), these data indicate that early lineage in the fish contributes nothing to the body pattern, as in the mouse.

In contrast, the frog has several indicators of polarity by the first cell cycle. A gradient of yolk platelets establishes the rostralcaudal (animal-vegetal) axis. Cytoplasmic movements cause the formation of a pigment granule gradient (i.e., the grey crescent) that usually denotes the dorsal-ventral axis (Gerhart et al., 1981). And the first cleavage furrow always approximates the plane of bilateral symmetry (Klein, 1987). Although the cleavages can occur in nearly any position, and still producc an outwardly normal embryo, there is a predominant sequence and pattern of furrow formations. The above-mentioned external markings of polarity make it possible to identify the same cell, based on relative position, in a selected population of embryos. By watching the first several cleavages, one can select embryos that share identifiable cells, with regard to ancestry, position, and content of egg cytoplasm that they inherit (described in greater detail in Moody, 1987a). This selection is expected to enhance our chances of finding any deterministic information harbored as stored cytoplasmic material or positional values.

In embryos sharing this stereotypic cleavage pattern, there is considerable regularity of cell fate (Kline and Moody, 1987; Moody, 1987a, b). These fates are not invariant; for example, in some embryos a particular blastomere may contribute a small number of cells to a particular organ, whereas in other embryos the same blastomere may contribute none. However, the overall patterns are strikingly consistent. In addition, study of the fates of "aberrant cleavages" indicates that fates are predictably altered according to the new placement of the cleavage furrows (Jacobson, 1981a; Masho, 1988). Thus, frog blastomeres resulting from stereotypic cleavage patterns express highly predictable progeny, with regard to spatial location and contribution to specific organ systems.

It is possible that this regularity in cell fate results either from the consistent position of each blastomere in the embryo or to lineage-specific instructions. Compatible with the first possibility is the striking organization of progeny in a spatial pattern, rather than according to phenotype, tissue, or primary germ layer. This spatial organization might result from the early establishment during the first cell cycle of the cardinal axes, as discussed above, or the extensive coherence of the blastomere clones during gastrulation movements (Jacobson and Klein, 1985; Moody, 1985; Wetts and Fraser, 1986). Alternatively, a segmental lineage pattern, such as has been described in leech (Weisblat, 1985), might exist. Unfortunately, to distinguish between positional and lineage control of this pattern is difficult in vertebrate species because of the large number of cells that make up the clones. Previous attempts to "pseudoquantify" progeny (Dale and Slack, 1987; Moody, 1987a, b) are too crude to confidently address this problem. Therefore, I have focused on counting the number of 2 kinds of neurons that descend from each blastomere and have used these data for quantitative analysis of the variation of fate between embryos and for exploring the possibility of segmental lineage patterns.

The results demonstrate that each blastomere produces a characteristic number of PMN and RB. This number is not 
Table 5. Average number of RB contributed by each 32CS blastomere to each segmental bin of spinal cord

\begin{tabular}{|c|c|c|c|c|c|c|c|c|c|}
\hline \multirow{2}{*}{$\begin{array}{l}\text { Blasto- } \\
\text { mere }\end{array}$} & \multicolumn{9}{|l|}{ Bin } \\
\hline & 1 & 2 & 3 & 4 & 5 & 6 & 7 & 8 & 9 \\
\hline D1.1.1 & 0.1 & 0 & 0.1 & 0 & 0.2 & 0 & 0.3 & 0 & 0.2 \\
\hline D1.1.2 & 0.1 & 0 & 0 & 0 & 0 & 0 & 0.2 & 0.1 & 0.2 \\
\hline D1.2.1 & 0.1 & 0.6 & 0.3 & 0.2 & 0.2 & 0.1 & 0 & 0.1 & 0.2 \\
\hline $\mathrm{D} 1.2 .2$ & 0.3 & 0.3 & 0.3 & 0.4 & 0.3 & 0.5 & 0.4 & 0.3 & 0.2 \\
\hline $\mathrm{D} 2.1 .2$ & 0 & 0 & 0 & 0 & 0.1 & 0 & 0.1 & 0 & 0 \\
\hline D2.1.1 & 0 & 0 & 0 & 0 & 0 & 0 & 0 & 0 & 0 \\
\hline $\mathrm{D} 2.2 .2$ & 0.4 & 0.6 & 0.5 & 0.2 & 0.5 & 0.4 & 0.5 & 0.5 & 0.7 \\
\hline $\mathrm{D} 2.2 .1$ & 0 & 0 & 0 & 0 & 0 & 0 & 0 & 0 & 0.1 \\
\hline V1.1.1 & 0.2 & 0.3 & 0.2 & 0.3 & 0.2 & 0.3 & 0.4 & 0.3 & 0.2 \\
\hline V1.1.2 & 0.4 & 0.3 & 0.4 & 0.7 & 0.6 & 0.9 & 0.7 & 0.5 & 0.4 \\
\hline V1.2.1 & 0.8 & 1.3 & 1.1 & 1.5 & 1.6 & 1.0 & 0.7 & 0.7 & 0.3 \\
\hline V1.2.2 & 0.2 & 1.0 & 2.0 & 1.2 & 1.2 & 1.3 & 1.0 & 0.7 & 0.3 \\
\hline V2.1.2 & 0.1 & 0.2 & 0.1 & 0.3 & 0.5 & 0.6 & 0.6 & 0.9 & 0.2 \\
\hline V2.1.1 & 0 & 0.2 & 0.1 & 0.2 & 0 & 0.1 & 0 & 0 & 0 \\
\hline V2.2.2 & 0.5 & 1.3 & 1.8 & 2.1 & 1.9 & 2.4 & 1.5 & 1.9 & 0.9 \\
\hline $\mathrm{V} 2.2 .1$ & 0 & 0.3 & 0.4 & 0.4 & 0.3 & 0.3 & 0.2 & 0.2 & 0.3 \\
\hline Total & 3.2 & 6.4 & 7.3 & 7.5 & 7.6 & 7.9 & 6.6 & 6.2 & 4.2 \\
\hline
\end{tabular}

invariant between embryos in which the same blastomere was injected but is statistically reliable within a large population, based on the small SEMs. ${ }^{1}$ In addition, the sum of all of the means at the $16 \mathrm{CS}$ is $100 \mathrm{PMN}$ and $58 \mathrm{RB}$, and the same sum at the $32 \mathrm{CS}$ is $98 \mathrm{PMN}$ and $59 \mathrm{RB}$. These sums are remarkably close, even though they are derived from hundreds of different individuals. Furthermore, these sums closely approximate the total number of normal cell counts reported previously (Lamborghni, 1980; Jacobson, 1981a; Jacobson and Moody, $1984)^{2}$. Thus, the sum of the mean numbers for each blastomere accounts for the total number, derived by independent means. However, this striking regularity in cell numbers does not distinguish between positional or lineage control since either could give rise to a consistent pattern. It does suggest that information regarding total cell number, and each blastomere's contribution thereof, is probably imparted early in development, possibly as

\footnotetext{
' A study similar to this one was performed previously on the Rohon-Beard population from 16CS Xenopus blastomeres (Jacobson, 1981a). In general, our results agree in naming V1.1, V1.2, and V2.2 as the major RB progenitors. However, the mean values obtained by Jacobson were nearly twice as large for V1.2 and V2.2, and half as large for V1.1, as compared with the values reported here. His means were within the range of my observations, so the differences in precise values probably are due to the very small population sample in his study $(n=2$ or 3 ). In addition, I reported at least some CNS progeny from every $16 \mathrm{CS}$ and 32CS blastomere (Moody, 1987a, b; present report), whereas Jacobson did not observe descendants in the CNS from some of these blastomeres (Jacobson, 1981a, 1984; Jacobson and Hirose, 1981). For example, I consistently observed RB descendants from dorsal, frontal plane blastomeres (D1.2, 11 out of 12 embryos; D2.2, 11 out of 12 embryos), and occasionally from midline embryos (D1.1, 10 out of 15 embryos; D2.1, 2 out of 12 embryos; V1.2, 5 out of 13 embryos). At the $32 \mathrm{CS}$, I observed that every blastomere contributes to the CNS, but to varying degrees (Moody, 1987b). For those blastomeres that Jacobson and Hirose (1981) did not consider to produce CNS, we observed a least a small contribution from at least 2 or more embryos. Again, it seems that the differences between studies can be explaincd by the differences in sample size, which cmphasizes that the inherent variation in Xenopus fate maps makes it necessary to study reasonably large populations.

${ }^{2}$ Our cell counts are based on stage $32-34$ embryos, in which there are approximately 32 segmented somites (Nieuwkoop and Faber, 1964). The total number of each primary neuron is stage dependent, in that up until stage 40 , more segments are added in the tail and more neurons differentiate. Therefore, this discussion is based only on the number of cells apparent at this small developmental window.
}

part of a global pattern, rather than near terminal branches of the lineage, at which time phenotype numbers in vertebrate clones seem to occur randomly (Turner and Cepko, 1987; Wetts and Fraser, 1988).

The number of PMN and RB descendants of a particular blastomere does vary among cmbryos. This variability may bc due to (1) small discrepancies in cleavage furrow placement; (2) inaccurate identifications of neuronal phenotypes based only on morphological features (especially in rostral sections where cranial motoneurons may have been included in the PMN counts; see Materials and Methods); (3) lineage marker-induced cell death or other effects of the manipulations; or (4) a natural indeterminancy in exact number of particular phenolypes from each progenitor. This variability, discussed in detail in the fate map studies (Moody, 1987a, b) indicates that Xenopus lineage is not indeterminant, especially compared with nematode and leech neuronal lineages (Weisblat et al., 1980a; White et al., 1982). However, it is far more regular than seen in other vertebrates (Ziomek et al., 1982; Pedersen et al., 1986; Kimmel and Warga, 1987). We do not understand how genetic (e.g., lineage) and epigenetic factors control neuron numbers in vertebrates (reviewed in Williams and Herrup, 1988), but even isogenic insects can have slightly different numbers of particular phenotypes (Goodman, 1977), suggesting that the various factors will be difficult to identify precisely. This is especially true in Xenopus, which is ancestrally tetraploid, and has an unknown extent of genomic diploidization (Kobel and DuPasquier, 1986).

A powerful predictive tool that cell counts provide is the ability to construct retrospective lineage diagrams (see Materials and Methods) for cell cycles at which we cannot directly obtain data because the clones are so large and densely populated. By comparing 2 adjacent stages, one can deduce the degree to which developmental fate is parceled to positionally distinct daughter cells. These analyses illustrate that there are predominant patterns of lineal descent. The arrowheads in Figure 4 denote which daughter produces the majority $(>61 \%)$ of their mother cell's value, and therefore estimate the predominant pattern of lineal 
descent for each primary neuron. It is striking that these patterns, albeit only estimates, frequently are nearly identical in different branches of the family tree (e.g., compare the D and $\mathrm{V}$ lineages for $\mathrm{RB}$ ). Comparison of the actual cell counts of the $16 \mathrm{CS}$ and $32 \mathrm{CS}$ (Table 1) with these percentages shows that not all of the lineage branch points indicated by arrowheads directed at only one daughter cell represent significant differences. At some points where one sister has a $>61 \%$ contribution, the actual means \pm SEM overlap those of its sister cell. Most of these points occur at the $32 \mathrm{CS}$ and involve blastomeres that contribute very few PMN (D2.1.2, V1.2.1) or RB (D2.1.2, V1.1.1). The rest of the lineage branch points at the $16 \mathrm{CS}$ and $32 \mathrm{CS}$ are characterized by sibling mean values \pm SEM that do not overlap (as indicated by asterisks in Fig. 4). Thus, the cell counts confirm in most cases $(69 \%)$ that the lineal descent pattern produced retrospectively probably represents a reasonable estimate of the true lineal pattern for PMN and RB. It is tempting to suggest that these estimates may indicate an underlying lineage-like pattern in an indeterminant vertebrate.

The retrospective lineage analysis also illustrates that major segregations in fate occur at the 4CS and that smaller segregations occur at the next 3 cell cycles to effectively eliminate some blastomeres as primary neuron progenitors. Apportioning neuronal fate so early suggests coincidental expression of some developmental information. Since the embryonic genome is not yet activated in frog (Newport and Kirschner, 1982), cytoplasmic determinants of positional information or tissue-type, or lineage-specified information, seem the most likely candidates. Recent evidence also implicates endogenous growth factors in cellular interactions or inductions (Kimelman and Kirschner, 1987). Observations of normal lineages alone probably will not indicate the interactions responsible for these early fate differences, but these interactions may be revealed by comparing the normal data base provided here to that derived from experimental manipulations.

\section{Contralateral progeny}

It is interesting that a few blastomeres consistently give rise to a few contralateral primary neurons (see also Jacobson, 1981a). These cells constitute only a small percentage of the total PMN or $\mathrm{RB}$ clones, yet they are significant because they suggest, as previously observed (Jacobson and Hirose, 1978; Klein, 1987) that the midsagittal boundary is not impenetrable. However, in comparison with the zebrafish, in which bilateral members of a neuronal clone in the spinal cord are very common (Kimmel and Warga, 1986), this feature is not prevalent in frog. Since it occurs most frequently in descendants of 3 most dorsal blastomeres, it may be due to the convergence/extension movements that occur during Xenopus gastrulation (Keller, 1984). In the mouse, the founder cells for bilateral brain stem and cerebellar structures may arise independently from one another (Herrup, 1987). Therefore, the midsagittal boundary may be respected to varying degrees in different vertebrates (fish, frog, and mouse), possibly depending upon their characteristically different gastrulation movements.

\section{Periodicity of descendants}

Segmentation of the animal body into iterated groups of different cell phenotypes is a common pattern across phyla, and certain segmental features may be influenced by lineage. For example, in the nematode, an unsegmented worm, the lateral hypodermis of the larva is divided into repeated units, each with its own progenitor cell (Sulston et al., 1983). In the truly segmented leech, each teloblast contributes the same few cells to each segment (Weisblat, 1985; Weisblat and Shankland, 1985). Each leech mesodermal segment is derived, via an invariant sequence of cell divisions, from a single primary mesoblast, suggesting that "reiterative lineages give rise to a metameric body plan" (Zackson, 1982). Insect epidermal clones are confined to single segments (Lawrence, 1973), and the expression of several genes has been associated with segmentation (Carroll et al., 1986; Scott and Carroll, 1987; Deutsch et al., 1988). All of these studies suggest that there may be intrinsic developmental control of this highly conserved body plan.

Many invertebrate neurons are segmentally arranged, but this pattern has been difficult to discern in vertebrates (reviewed in Hanneman et al., 1988; Keynes and Stern, 1988). However, there is compelling evidence for neuromeres, CNS segments, and iterated cell clusters in the zebrafish (Hanneman et al., 1988). In fact, 3 identifiable PMN in zebrafish repeat with every somitic segment (Myers et al., 1986; Westerfield et al., 1986). Furthermore, clones established in the gastrula frequently (in $90 \%$ of the cases) dispersed in a periodic fashion along the embryonic axis (Kimmel and Warga, 1986).

In Xenopus, the difficulty in preparing optically clear spinal cord/somite preparations at early tail bud stages, because of yolk platelets within all of the cells, has made it difficult to establish whether similar periodic clusters occur in the spinal cord, and are in register with the somitic segments. However, dividing the total number of PMN per side (100) by the total number of somitic segments ( 32 at stage $33 / 34$; Nieuwkoop and Faber, 1967) suggests the possibility of 3 PMN per segment, as exist in zebrafish. Determining whether the clones giving rise to these neurons are periodically dispersed could be done only by estimating PMN positions into segmental bins that spanned approximately 2 somites. As a population, there is a tendency for those blastomeres that are major progenitors for PMN or $\mathrm{RB}$ to contribute to every segmental bin, those that are lesser progenitors to contribute mostly to one axial region (i.e., rostral or caudal), and those that hardly contribute any cells to place their progeny randomly along the axis. Thus, there is support for periodicity only among the major progenitors of PMN and $\mathrm{RB}$. Occasional blastomeres contributed 1-2 primary neurons to nearly every segmental bin, possibly indicating periodic axial distribution of progeny. However, these data are not precise enough to claim a segmental lineage pattern for the frog.

\section{References}

Blight, A. R. (1978) Golgi-staining of "primary" and "secondary" motoneurons in the developing spinal cord of an amphibian. J. Comp. Neurol. 180: 679-690.

Carroll, S. B., G. M. Winslow, T. Schüpbach, and M. P. Scott (1986) Maternal control of Drosophila segmentation gene expression. Nature 323: 278-280.

Clarke, J. D. W., B. P. Hayes, S. P. Hunt, and A. Roberts (1984) Sensory physiology, anatomy and immunocytochemistry of RohonBeard neurones in embryos of Xenopus laevis. J. Physiol. (Lond.) 348: $511-525$.

Coghill, G. E. (1913) The primary ventral roots and somatic motor column of Amblystoma. J. Comp. Neurol. 23: 121-143.

Conklin, E. G. (1905) The organization and cell-lineage of the ascidian egg. J. Acad. Natl. Sci. (Phila.) 13: 1-119.

Dale, L., and J. M. W. Slack (1987) Fate map for the 32-cell stage of Xenopus laevis. Development 99: 527-551.

Deutsch, U., G. R. Dressler, and P. Gruss (1988) Pax 1, a member of 
a paired box homologous murine gene family, is expressed in segmented structures during development. Cell 53:617-625.

Gerhart, J., G. Ubbels, S. Black, K. Hara, and M. Kirschner (1981) A reinvestigation of the role of the grey crescent in axis formation in Xenopus laevis. Nature 292: 511-516.

Gimlich, R. L., and J. C. Gerhart (1984) Early cellular interactions promote embryonic axis formation in Xenopus laevis. Dev. Biol. 104: $117-130$.

Goodman, C. (1976) Constancy and uniqueness in a large population of small intcrncurons. Scicnce 193: 502-504.

Goodman, C. S. (1977) Neuron duplications and deletions in locust clones and clutches. Science 197: 1384-1386.

Hamilton, L. (1969) The formation of somites in Xenopus. J. Embryol. Exp. Morphol. 22: 253-264.

Hanneman, E., B. Trevarrow, W. K. Metcalfe, C. B. Kimmel, and M. Westerfield (1988) Segmental pattern of development of the hindbrain and spinal cord of the zebrafish embryo. Development 103:4958.

Heasman, J., C. C. Wylie, P. Hausen, and J. C. Smith (1984) Fates and states of determination of single vegetal pole blastomeres of Xenopus laevis. Cell 37: 185-194.

Herrup, K. (1987) Roles of cell lineage in the developing mammalian brain. Current Topics Dev. Biol. 21: 65-97.

Hirosc, G., and M. Jacobson (1979) Clonal organization of the central nervous system of the frog. I. Clones stemming from individual blastomeres of the 16-cell and earlier stages. Dev. Biol. 71: 191-202.

Hughes, A. F. (1957) The development of the primary sensory system in Xenopus laevis (Daudin). J. Anat. 91: 323-338.

Hughes, A. F. (1959) Studies in embryonic and larval development in amphibia. II. The spinal motor root. J. Embryol. Exp. Morphol. $7: 128-145$

Jacobson, M. (1981a) Rohon-Beard neuron origin from blastomeres of the 16-cell frog embryo. J. Neurosci. 1: 918-922.

Jacobson, M. (1981b) Rohon-Beard neurons arise from a substitute ancestral cell after removal of the cell from which they normally arise in the 16-cell frog embryo. J. Neurosci. 1: 923-927.

Jacobson, M. (1983) Clonal organization of the central nervous system of the frog. III. Clones stemming from individual blastomeres of the 128-, 256-, and 512-cell stages. J. Neurosci. 3: 1019-1038.

Jacobson, M. (1984) Cell lineage analysis of neural induction: Origins of cells forming the induced nervous system. Dev. Biol. 102: 122129.

Jacobson, M., and G. Hirose (1978) Origin of the retina from both sides of the embryonic brain: A contribution to the problem of crossing at the optic chiasma. Science 202: 637-639.

Jacobson, M., and G. Hirose (1981) Clonal organization of the central nervous system of the frog. II. Clones stemming from individual blastomeres of the 32- and 64-cell stages. J. Neurosci. 1: 271-284.

Jacobson, M., and S. L. Klein (1985) Analysis of clonal restriction of cell mingling in Xenopus. Phil. Trans. R. Soc. London [Biol.] 312: $57-65$.

Jacobson, M., and S. A. Moody (1984) Quantitative lineage analysis of the frog's nervous system. I. Lineages of Rohon-Beard neurons and primary motoneurons. J. Neurosci. 4: 1261-1369.

Keller, R. E. (1975) Vital dye mapping of the gastrula and neurula of Xenopus laevis. I. Prospective areas and morphogenetic movements of the superficial layer. Dev. Biol. 42: 222-241.

Keller, R. E. (1984) The cellular basis of gastrulation in Xenopus laevis: Active postinvolution, convergence and extension by mediolateral interdigitation. Am. Zool. 24: 589-603.

Keynes, R. J., and C. D. Stern (1988) Mechanisms of vertebrate segmentation. Development 103: 412-429.

Kimelman, D., and M. Kirschner (1987) Synergistic induction of mesoderm by FGF and TGF- $\beta$ and the identification of an mRNA coding for FGF in the early Xenopus laevis embryo. Cell 51: 869-877.

Kimmel, C. B., and R. D. Law (1985a) Cell lineage of zebrafish blastomeres. I. Cleavage pattern and cytoplasmic bridges between cells. Dev. Biol. 108: 78-85.

Kimmel, C. B., and R. D. Law (1985b) Cell lineage of zebrafish blastomeres. III. Clonal analyses of the blastula and gastrula stages. Dev. Biol. 108: 94-101.

Kimmel, C. B., and R. M. Warga (1986) Tissue-specific cell lineages originate in the gastrula of the zebrafish. Science 231: 365-368.

Kimmel, C. B., and R. W. Warga (1987) Indeterminate cell lineage of the zebrafish embryo. Dev. Biol. 124: 269-280.
Klein, S. L. (1987) The first cleavage furrow demarcates the dorsalventral axis in Xenopus embryos. Dev. Biol. 120: 299-304.

Kline, M. J., and S. A. Moody (1987) Fates of the blastomeres of the 4- and 8-cell stage frog (Xenopus laevis) embryos. Anat. Rec. 218. $73 \mathrm{~A}$.

Kobel, H. R., and L. DuPasquier (1986) Genetics of polyploid Xenopus. Trends Genet. 2: 310-315.

Konigsmark, B. W. (1970) Methods for the counting of neurons. In Contemporary Research Methods in Neuroanatomy, W. J. H. Nauta and S. O. E. Ebbeson, eds., pp. 315-340, Springer-Verlag, New York.

Lamborghini, J. E. (1980) Rohon-Beard cells and other large neurons in Xenopus embryos originate during gastrulation. J. Comp. Neurol. 189: 323-333.

Lawrence, P. A. (1973) A clonal analysis of segment development in Oncopeltus (Hemiptera). J. Embryol. Exp. Morphol. 30: 681-699.

Masho, R. (1988) Fates of animal-dorsal blastomeres of eight-cell stage Xenopus embryos vary according to the specific patterns of the third cleavage plane. Dev. Growth Differ. 30: 347-359.

Masho, R., and H. Y. Kubota (1986) Developmental fates of blastomeres of eight-cell-stage Xenopus laevis embryos. Dev. Growth Differ. 28: 113-123.

Moody, S. A. (1985) Gastrulation movements of progeny derived from 16-cell stage Xenopus blastomeres. J. Cell. Biochem. 8B: 78.

Moody, S. A. (1987a) Fates of the blastomeres of the 16-cell stage Xenopus embryo. Dev. Biol. 119: 560-578.

Moody, S. A. (1987b) Fates of the blastomeres of the 32-cell stage Xenopus embryo. Dev. Biol. 122: 300-319.

Muntz, L. (1964) Neuromuscular Foundations of Behavior in Early Stages of the Anuran, Xenopus laevis. Doctoral Dissertation, University of Bristol, Bristol, England.

Myers, P. Z., J. S. Eisen, and M. Westerfield (1986) Development and axonal outgrowth of identified motoneurons in the zebrafish. J. Neurosci. 6: 2278-2289.

Nakamura, O., H. Takasaki, and A. Nagata (1978) Further studies of the prospective fates of blastomeres at the 32-cell stage of Xenopus laevis embryos. Med. Biol. 56: 355-360.

Newport, J., and M. Kirschner (1982) A major developmental transition in early Xenopus embryos. I. Characterization and timing of cellular changes at the midblastula stage. Cell 30:675-686.

Nieuwkoop, P. D., and J. Faber (1964) Normal Table of Xenopus laevis (Daudin), 2nd ed., Elsevier-North Holland, Amsterdam.

Nordlander, R. H. (1984) Developing descending neurons of the early Xenopus tail spinal cord in the caudal spinal cord of early Xenopus. J. Comp. Neurol. 228: 117-128.

Pedersen, R. A., K. Wu, and H. Balakier (1986) Origin of the inner cell mass in mouse embryos: Cell lineage analysis by microinjection. Dev. Biol. 117: 581-595.

Roberts, A., and J. D. W. Clarke (1982) The neuroanatomy of an amphibian embryo spinal cord. Phil. Trans. R. Soc. Iondon [Biol.] 196: 195-212.

Roberts, A., J. A. Kahn, S. R. Soffe, and J. D. W. Clarke (1981) Neural control of swimming in a vertebrate. Science 213: 1032-1034.

Scott, M. P., and S. B. Carroll (1987) The segmentation and homeotic gene network in early Drosophila development. Cell 51: 689-698.

Stehouwer, D. J., and P. B. Farel (1980) Central and peripheral controls of swimming in anuran larvae. Brain Res. 195: 323-335.

Sulston, J. E., and H. R. Horvitz (1977) Postembryonic cell lineages of the nematode, Caenorhabditis elegans. Dev. Biol. 56: 110-156.

Sulston, J. E., E. Schierenberg, J. G. White, and J. N. Thomas (1983) The embryonic cell lineage of the nematode Caenorhabditis elegans. Dev. Biol. 100: 64-119.

Takasaki, H. (1987) Fates and roles of the presumptive organizer region in the 32-cell embryo in normal development of Xenopus laevis. Dev. Growth Differ. 29: 141-152.

Turner, D. L., and C. L. Cepko (1987) A common progenitor for neurons and glia persists in rat retina late in development. Nature 328: 131-136.

Vogt, W. (1929) Gestaltunganalyse am Amphibienkeim mit örtlicher. Vitalfärbung. II. Teil. Gastrulation und Mesodermbildung bei Urodelen und Anuren. Wilhelm Roux Arch. Entw. Mech. Org. 120: 384706.

Weisblat, D. A. (1985) Segmentation and commitment in the leech embryo. Cell 42: 701-702.

Weisblat, D. A., and M. Shankland (1985) Cell lineage and segmentation in the leech. Phil. Trans. R. Soc. London [Biol.] 312: 39-56. 
Weisblat, D. A., R. T. Sawyer, and G. S. Stent (1978) Cell lineage analysis by intracellular injection of a tracer. Science 202: 1295-1298.

Weisblat, D. A., G. Harper, G. S. Stent, and R. T. Sawyer (1980a) Embryonic cell lineages in the nervous system of the glossiphoniid leech Helobdella triserialis. Dev. Biol. 76: 58-78.

Weisblat, D. A., S. L. Zackson, S. S. Blair, and J. D. Young (1980b) Cell lineage analysis by intracellular injection of fluorescent tracers. Science 209: 1538-1541.

Westerfield, M., J. V. McMurray, and J. S. Eisen (1986) Identified motoneurons and their innervation of axial muscles in the zebrafish. J. Neurosci. 6: 2267-2277.

Wetts, R., and S. E. Fraser (1986) Fate mapping of blastomeres involved in Xenopus neural development: Slow intermixing of cells. Soc. Neurosci. Abstr. 12: 1121.
Wetts, R., and S. E. Fraser (1988) Multipotent precursors can give rise to all major cell types of the frog retina. Science 239: 1142-1 145.

White, J. G., H. R. Horvitz, and J. Sulston (1982) Neuron differentiation in cell lineage mutants of Caenorhabditis elegans. Nature 297: 584-586.

Williams, R. W., and K. Herrup (1988) The control of cell number. Annu. Rev. Neurosci. 11: 423-453.

Zackson, S. L. (1982) Cell clones and segmentation in leech development. Cell 31: 761-770.

Ziomek, C. A., M. H. Johnson, and A. H. Handyside (1982) The developmental potential of mouse 16-cell blastomeres. J. Exp. Zool. 221: 345-355. 